This paper reports a study into the regularities of interphase interaction, features in the formation of intermetallic phases (IMPs), and defects when surfacing steel on titanium in four ways: P-MAG, CMT, plasma surfacing by an indirect arc with conductive wire, and PAW. A general tendency has been established in the IMP occurrence when surfacing steel on titanium by all the considered methods. It was determined that the plasma surfacing technique involving an indirect arc with conductive wire is less critical as regards the IMP formation. That makes it possible to obtain an intermetallic layer of the minimum thickness $(25 . .54 \mu \mathrm{m})$ in combination with the best quality in the formation of surfaced metal beads. Further minimization of the size of this layer is complicated by a critical decrease in the heat input into the metal, which gives rise to the capability of the surfaced metal to be collected in separate droplets. The formation of $\mathrm{TiFe}_{2}$, TiFe, and the a-Fe phase enriched with titanium in different percentage compositions has been observed in the transition zone of steel surfacing on titanium under different techniques and modes of surfacing. The study has shown the possibility of formation, in addition to the phases of $\mathrm{TiFe}_{2}$ and $\mathrm{TiFe}$, the Ti ${ }_{2}$ Fe phase at low heat input. The technique of plasma surfacing by an indirect arc with conductive wire minimizes the thermal effect on the base metal. When it is used at the border of the transition of the layer of steel surfaced on titanium, the phase composition and structure of the layers in some cases approach the composition and structure of the transition zone of the original bimetallic sheet "titanium-steel" manufactured by rolling. A layer up to 5 um thick is formed from the $\beta$ phase with an iron concentration of $44.65 \%$ by weight and an intermetallic layer up to 0.2...0.4 um thick, close in composition to the TiFe phase. The next step in minimizing the IMP formation might involve the introduction of a barrier layer between titanium and steel

Keywords: steel, titanium, intermetallic phases, formation of beads, fusion zone

\section{COMPARING FEATURES IN METALLURGICAL INTERACTION WHEN APPLYING DIFFERENT TECHNIQUES OF ARC AND PLASMA SURFACING OF STEEL WIRE ON TITANIUM}

Volodymyr Korzhyk

Doctor of Technical Sciences,

Corresponding Member of the National Academy of Sciences of Ukraine, Head of Department*

VIadys Iav Khaskin

Corresponding author

Doctor of Technical Sciences, Leading Researcher

Department of Laser Welding***

E-mail: khaskin@ukr.net

A ndri i G r n y u k

$\mathrm{PhD}$, Researcher

Department of Electrothermal Processes of Material Processing**

Oleg Ganushchak

Head of Department

Department of Innovative Technologies**

S viatoslav Peleshenko

Postgraduate Student

Department of Welding Production

National Technical University of Ukraine "Igor Sikorsky Kyiv Polytechnic Institute" Peremohy ave., 37, Kyiv, Ukraine, 03056

Oksana Konoreva

$\mathrm{PhD}$, Senior Researcher*

Oleksi Demianov

$\mathrm{PhD}$, Deputy Head of Department*

Volodym yr Shcheretskiy

$\mathrm{PhD}$, Senior Researcher

Department of Composite Materials

Physico-Technological Institute of Metals and Alloys of the National Academy of Science of Ukraine

Vernadskoho blvd., 34/1, Kyiv, Ukraine, 03142

Nataliia Fialko

Doctor of Technical Sciences, Professor, Corresponding Member

of the National Academy of Sciences of Ukraine

Department of Thermophysics of Energy-Efficient Heat Technologies Institute of Engineering Thermophysics of the National Academy of Sciences of Ukraine

Mariyi Kapnist (Zheliabova) str., 2a, Kyiv, Ukraine, 03057

*Department of Electrothermal Processes of Materials Treatment** $\star *$ E .O. Paton Electric Welding Institute of the National Academy of Sciences of Ukraine Kazymyra Malevycha str., 11, Kyiv, Ukraine, 03150 $* * *$ Guangdong Welding Institute (E.O. Paton Chinese-Ukrainian Institute of Welding) Changxing Road, 363, Tian He, Guangzhou, China, 510650
Received date 06.07.2021 Accepted date 09.08.2021 Published date 26.08.2021
How to Cite: Korzhyk, V., Khaskin, V., Grynyuk, A., Ganushchak, O., Peleshenko, S., Konoreva, O., Demianov, O., Shcheretskiy, V., Fialko, $N$. (2021). Comparing features in metallurgical interaction when applying different techniques of arc and plasma surfacing of steel wire on titanium. Eastern-European Journal of Enterprise Technologies, 4 (12 (112)), 6-17. doi: https://doi.org/10.15587/1729-4061.2021.238634

\section{Introduction}

In the manufacture of modern pipelines intended for the transportation of gas and petroleum products, special atten- tion is paid to prolonging their operational service life. To this end, the pipes for such pipelines are made of steel clad with a layer of titanium or titanium alloy $[1,2]$. The presence of a titanium layer and the high requirements for the strength 
and corrosion resistance of welds predetermine a series of problems when choosing techniques for welding titanium-clad steel blanks in order to manufacture bimetallic pipes.

It is a relevant task to choose a technique and devise technology for welding sheets of titanium-clad steel, which, at relatively low cost, would make it possible to obtain joints of the required quality. Underlying a solution to this problem is the process of surfacing steel welding wire on a titanium substrate. It is known, for example, from work [3], that, in this case, undesirable intermetallic phases (IMPs) could form, leading to the destruction of compounds. There are various procedures to eliminate the risk of such phases but all of them, to some extent, are based on reducing the thermal effect of the surfaced steel layer on the titanium layer. It is necessary to study the features of the metallurgical interaction of steel wire surfacing on titanium under the conditions of application of various arc and plasma processes. That would make it possible to choose a protection technique against IMP formation, as well as the technological methods for welding sheets of titanium-clad steel.

\section{Literature review and problem statement}

The main issue related to welding butt joints of sheets of steel clad with a layer of titanium is the danger of IMP formation, the type of $\mathrm{Fe}_{2} \mathrm{Ti}$, and FeTi [4]. According to work [4], that could lead to the formation of cold cracks and further destruction of welded joints. Paper [5] noted that the solubility of iron in $\alpha$-titanium is extremely small and, at room temperature, is within 0.05 to $0.1 \%$. At a concentration exceeding $0.1 \% \mathrm{Fe}$ in the alloy, IMPs of $\mathrm{TiFe}$ and $\mathrm{TiFe}_{2}$ types are formed. The presence of IMP in the compound of Ti with Fe significantly increases its strength but dramatically reduces its plasticity. The latter could lead to the destruction of such compounds. According to the phase diagram given in work [5], it is also possible to form a $\mathrm{Ti}_{2} \mathrm{Fe}$ compound.

Work [6] argues that the $\mathrm{TiFe}_{2}$ compound crystallizes with an open maximum at $1,427^{\circ} \mathrm{C}$ and has a wide enough region of homogeneity in the range of up to $10 \%$ (at.) at $1,300{ }^{\circ} \mathrm{C}$. With a decrease in temperature, this region narrows slightly. The TiFe compound is formed in line with a peritectic reaction at $1,317^{\circ} \mathrm{C}$, the region of its homogeneity does not exceed $\sim 4 \%$ (at.). The maximum solubility of titanium in $\alpha$-Fe does not exceed $9.8 \%$ (at.). At $1,289^{\circ} \mathrm{C}$, the eutectics $\mathrm{TiFe}_{2}+\alpha$-Fe crystallizes. The solubility of titanium in $\gamma$-Fe at $1,100{ }^{\circ} \mathrm{C}$ is $\sim 1.0 \%$ (at.). On the part of titanium, at $1,085{ }^{\circ} \mathrm{C}$, the eutectics $\mathrm{TiFe}+\beta$-Ti crystallizes; the eutectic point is at $\sim 71 \%$ (at.) Ti. The maximum solubility of iron in $\beta$-Ti reaches $22 \%$ (at.). At about $590{ }^{\circ} \mathrm{C}$, a eutectoid reaction occurs $\beta$-Ti $\leftrightarrow \mathrm{TiFe}+\alpha$-Ti. The solubility of iron in $\alpha$-Ti is insignificant - at a eutectoid temperature of up to $0.44 \%$ (at), at $400{ }^{\circ} \mathrm{C}$, it decreases to $0.34 \%$ (at.). The solubility of titanium in $\alpha$-Fe reaches $3.08 \%$ (at.) at $900{ }^{\circ} \mathrm{C}$, decreasing to $1.86 \%$ (at.) at $600{ }^{\circ} \mathrm{C}$. In the $\mathrm{Fe}$-Ti state diagram given in [6], a hypothetical possibility of formation, at temperatures above $1,085^{\circ} \mathrm{C}$, of the $\mathrm{Ti}_{2} \mathrm{Fe}$ compound containing $\sim 60 \% \mathrm{Ti}$ and about $30 \% \mathrm{Fe}$ is shown.

In work [7], the presence of the $\mathrm{Fe}_{2} \mathrm{Ti}$ and FeTi phases was confirmed while the hypothesis about the possibility of forming the $\mathrm{Ti}_{2} \mathrm{Fe}$ phase was not considered. In paper [8], the dual Fe-Ti system was re-evaluated using the CALPHAD method to improve the possibility of extrapolation to a triple or higher-order system. Compared to previous estimates, the focus was on the thermodynamic description of the two intermetallic compounds $\mathrm{Fe}_{2} \mathrm{Ti}$ and FeTi. No presence of the $\mathrm{Ti}_{2} \mathrm{Fe}$ IMP was confirmed. Therefore, one of the objectives of a given study was to test the possibility of the formation of the $\mathrm{Ti}_{2} \mathrm{Fe}$ phase in the transition zone during arc welding of steel on titanium.

IMPs in combination with high hardness have high brittleness and lead to a decrease in the strength of the welded joint until its destruction. To eliminate this problem, it is customary in world practice to use barrier layers created between steel and titanium, which protect against their mixing during welding. The recommended materials of such layers include vanadium [9], niobium [9], copper [9, 10], nickel [11], etc. The choice of the layer depends on the welding technique, the type of joint, performance, etc. One of the general criteria for choosing the type and geometry of the layer to be considered is the heat input into the welded metal, generated by a thermal source that provides the surfacing of layers of steel (or titanium) on top of the barrier layer. At the same time, the most interesting are such sources that are used in arc techniques of welding and surfacing. Employing these methods, it is possible to ensure maximum productivity at minimal cost, and, therefore, from the point of view of the industry, they are a priority [12].

However, the application of arc techniques of welding and surfacing, given their low thermal locality, requires a significant increase in the thickness of the barrier layers, which leads to additional technical difficulties and increases the cost of welded joints. Replacing arc techniques with more thermally local ones, for example, laser [9], is not always economically justified. Therefore, it is necessary to find a balance between the heat input into a welded metal at one or another arc technique and the possibility of creating an effective obstacle to the formation of IMP when it is used.

The first step towards finding this balance is the selection of such arc techniques of welding and surfacing that are able to provide sufficient thermal locality [13]. One of the approaches to investigate this issue is to study the features of the metallurgical interaction in the surfacing of steel wire on titanium or its alloy.

\section{The aim and objectives of the study}

The purpose of this study is to determine the relevance of using various techniques of arc surfacing in the IMP formation and the quality of the resulting beads of surfaced metal during butt welding with cutting steel sheets clad with a layer of titanium.

To accomplish the aim, the following tasks have been set:

- to choose the investigated techniques of arc surfacing;

- to study experimentally the degree of influence of the pulsed surfacing by a consumable electrode (P-GMAW or P-MAG) on the quality of the surfaced bead and the tendency to form IMPs;

- to investigate experimentally the degree of influence of surfacing with a consumable electrode using the "cold metal transfer" (CMT) method on the quality of the surfaced bead and the tendency to form IMPs;

- to explore experimentally the degree of influence of the plasma surfacing by an indirect arc with a current-carrying filler wire on the quality of the surfaced bead and the tendency to form IMPs;

- to examine experimentally the degree of influence of plasma-arc surfacing with current-carrying filler wire 
(PAW) on the quality of the surfaced bead and the tendency to form IMPs.

\section{The study materials and methods}

A likely procedure for welding bimetallic sheets of steel, grade Q235, thickness $\delta=10 \mathrm{~mm}$, clad with a layer of titanium, grade VT1-0, thickness $\delta=2 \mathrm{~mm}$ (Table 1), involves the following:

- cutting edges to release the joined titanium layers $(\delta=2 \mathrm{~mm})$ from steel (the reach of the edges of the titanium layer is $3-4 \mathrm{~mm}$ on each side);

- butt welding titanium layers using a TIG technique to minimize the size of the thermal influence zone (TIZ) and obtain a seam width of $2-3 \mathrm{~mm}$;

- defining the need and method of applying a barrier coating on the welded titanium layer, as well as (if necessary) the coating material (for example, the barrier layer can be surfaced by the pulsed surfacing with a consumable electrode (according to the international classification, Pulse Metal Active Gas - P-MAG) or sprayed by plasma);

- preparing the steel layer using one of the techniques of arc surfacing.

Taking into consideration the width of the seam and TIZ after TIG welding of the titanium layer, grade VT1-0, the prepared steel layer should have a width in the lower part of 6-8 $\mathrm{mm}$, the upper - at least $10-12 \mathrm{~mm}$. To reduce the thermal load on the welded titanium layer (and the barrier layer, in the case of its application), it is advisable to prepare the steel in several runs. For this purpose, the welding wire ER70S-6 (compliant with AWS A5.17, GOST 2246-70, EN 13479 ISO 143341, DIN 8559) with a diameter of $1.0 \mathrm{~mm}$ (Table 1) can be used. It is desirable to fill the prepared lower part with transverse vibrations of the welding torch. Instead, two parallel runs can be executed so that the welded layer of steel fuses with the preparation wall, titanium layer, or barrier layer, and the surfaced metal of the adjacent run.

The following research procedure was adopted for our work:

- select surfacing techniques (P-GMAW/P-MAG, CMT, plasma surfacing by indirect arc with conductive filler wire, PAW);

- select the criteria for obtaining surfaced beads - the quality of their formation and their geometric parameters (height and width);

- surface the wire ER70S-6 $(\varnothing 1.0 \mathrm{~mm})$ on a titanium plate, grade VT1-0 $(\delta=2.0 \mathrm{~mm})$ by the selected techniques in accordance with the chosen criteria;

- cut the obtained samples across the surfacing tracks, cut out transverse templates, manufacture, etch the microsections chemically (4\% alcohol solution $\mathrm{HNO}_{3}$ );

- study the microstructures of samples by optical (the microscope Neophot-31, Carl Zeiss, Zeiss AG, Germany) and electron (the microscope CamScan-4, CamScan, UK) microscopy;

- determine the distribution of components in the fusion zone and in the surfaced metal using electron probe analysis performed at the CamScan-4 electron microscope (CamScan, UK);

- determine the components, the existence and composition of IMP using X-ray spectral microanalysis (XSMA), performed at the microanalyzer "CAMEBAX" (Cameca, France).
Table 1

The chemical composition of materials used

\begin{tabular}{|c|c|c|c|c|c|c|c|c|c|}
\hline \multicolumn{1}{|c|}{ Elemental content, \% by weight } \\
\hline $0.14-0.22$ & $0.05-0.15$ & $0.4-0.65$ & $<0.3$ & $<0.3$ & $<0.3$ & - & - & $<0.04$ & $<0.05$ \\
\hline$<0.07$ & $<0.1$ & - & - & - & - & - & - & - & - \\
\hline$<0.08$ & $0.7-0.95$ & $1.8-2.1$ & $<0.25$ & $<0.2$ & $<0.25$ & - & - & $<0.03$ & $<0.025$ \\
\hline
\end{tabular}

\section{5 . The results of studying the interaction between steel and titanium when using various techniques of arc surfacing}

\section{1. Selecting the investigated techniques of arc sur-} facing

The choice of the studied techniques of surfacing was determined by the task to be solved - butt welding of sheets of steel, grade Q235 $(\delta=10 \mathrm{~mm})$, clad with a layer of titanium, grade VT1-0 $(\delta=2 \mathrm{~mm})$. A preliminary study of the initial bimetallic sheets showed that the titanium-steel interface is characterized by the presence of a transition zone about $5 \mu \mathrm{m}$ thick, consisting of the $\alpha$-Ti phase, supersaturated by iron concentration (about 5.5-12 wt. \%). Near the contact surface of this transition zone, at the interface of the steel side, there is a $\beta$ phase, with a high concentration of iron (44.65 wt. \%). As a result of further decay of the $\beta$ phase in this transition zone, a clearly visible intermetallic layer with a thickness of up to $0.2 \ldots 0.4 \mu \mathrm{m}$ is formed on the part of the steel, close in composition to the intermetallic TiFe (Fig. 1, Table 2).

Table 2

The content of elements in the transition zone sites of the bimetallic TiFe sheet (Fig. 1, c), determined by X-ray spectral microanalysis

\begin{tabular}{|c|c|c|c|}
\hline \multirow{2}{*}{ Spectrum } & \multicolumn{3}{|c|}{ Chemical composition, \% by weight } \\
\cline { 2 - 4 } & $\mathrm{Ti}$ & $\mathrm{Fe}$ & Total \\
\hline Spectrum 1 & 1.47 & 98.53 & 100 \\
\hline Spectrum 2 & 87.24 & 12.76 & 100 \\
\hline Spectrum 3 & 55.35 & 44.65 & 100 \\
\hline Spectrum 4 & 94.48 & 5.52 & 100 \\
\hline Spectrum 5 & 92.85 & 7.15 & 100 \\
\hline Spectrum 6 & 90.77 & 9.23 & 100 \\
\hline Spectrum 7 & 100 & - & 100 \\
\hline Spectrum 8 & 100 & - & 100 \\
\hline Spectrum 9 & 95.64 & 4.36 & 100 \\
\hline
\end{tabular}

When filling the cutting, the steel wire (ER70S-6 (Sv08G2S), Fig. 2, Table 1) must be surfaced under an automatic mode that provides for sufficient thermal locality. To this end, one can use plasma arc welding (PAW), which exploits an electrode made of tungsten while plasma gas is used to create an arc [13]. Due to the high enough intensity of the compressed arc, plasma-arc welding achieves a greater thermal locality than with gas-tungsten welding (GTAW). The advantage of welding in an inert (MIG) or active (MAG or GMAW) gas environment is the direct melting of the electrode wire by an arc burning between this wire and the part [13]. In the case of pulsed welding current, the thermal 
locality of this technique could be increased. Relatively recently, Cold Metal Transfer technology has revolutionized the welding of dissimilar metals and materials of greater thickness, creating an improved aesthetic appearance of the weld with controlled metal transfer and low heat input [14]. Given the high enough thermal locality, this technology is also of interest for research. Soft (that is weakly compressed) plasma arc of variable polarity is usually used to solve tasks related to welding aluminum alloys $[15,16]$. The process of surfacing with soft plasma (more precisely, plasma surfacing with an indirect arc with a conductive filler wire) has a reduced arc pressure, which helps maintain a stable keyhole in the welding bath. Such a process is also of interest.

Considering the task related to reducing heat input, the following techniques for fusing the groove in a steel layer [13-16] were chosen:

- pulsed, by a consumable electrode (P-GMAW or P-MAG);

- consumable electrode "cold metal transfer" (CMT);

- plasma, by an indirect arc with conductive filler wire;

- plasma-arc with conductive filler wire (PAW).

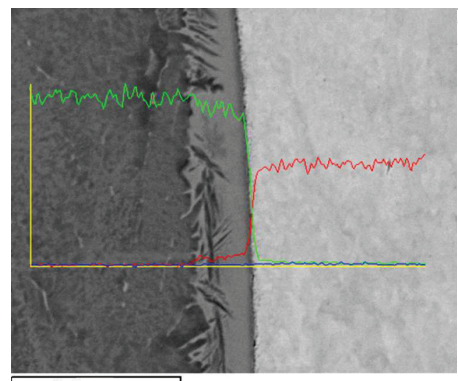

$30 \mu \mathrm{m}$

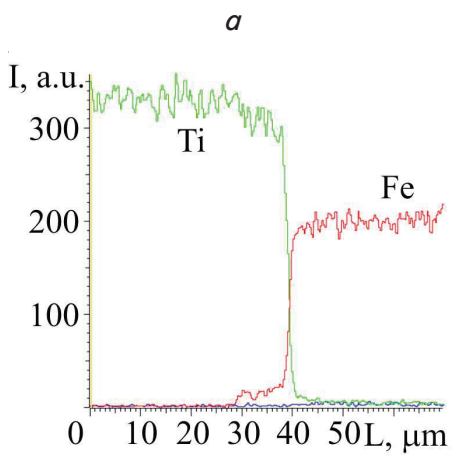

$b$

Sp. 1

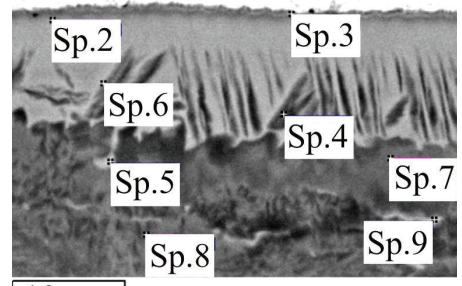

$10 \mu \mathrm{m}$

$c$

Fig. 1. Preliminary study of the Ti-Fe transition zone of the initial bimetallic sheets: $a$ - structure; $b$-distribution of components (electron probe analysis CamScan-4);

$c-$ areas whose composition was determined by X-ray spectral microanalysi

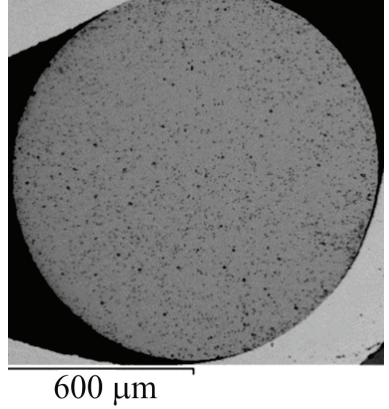

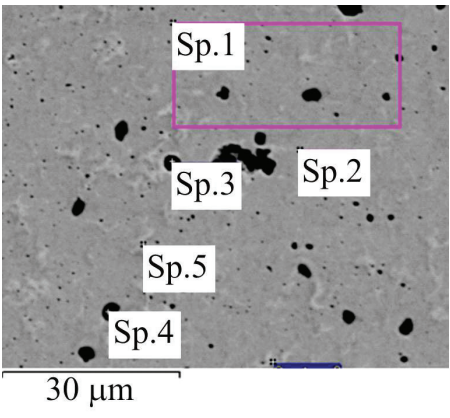

Fig. 2. The structure of steel wire ER70S-6: $a-$ transverse macro-section; $b$ - microstructure with an indication of zones for determining the chemical composition

5. 2. Investigating the influence of P-GMAW/P-MAG surfacing on the bead quality and the tendency to form intermetallic phases

To conduct the experiments, the welding power source TransSteel 3500/5000 from Fronius (Austria) was used. The copper wire ER70S-6 was surfaced with transverse vibrations of the welding torch on a pre-cleaned and degreased plate made of VT1-0 using a protective gas, which was a mixture of $82 \%$ $\mathrm{Ar}+18 \% \mathrm{CO}_{2}$. Surfacing modes are given in Table 3 .

Table 3

Bead surfacing modes using the P-GMAW technique

\begin{tabular}{|c|c|c|c|c|c|c|c|}
\hline $\begin{array}{c}\text { Mode } \\
\text { No. }\end{array}$ & $\begin{array}{c}\text { Weld- } \\
\text { ing } \\
\text { current, } \\
\mathrm{A}\end{array}$ & $\begin{array}{c}\text { Arc } \\
\text { volt- } \\
\text { age, } \\
\mathrm{V}\end{array}$ & $\begin{array}{c}\text { Protec- } \\
\text { tive gas } \\
\text { flow rate, } \\
\text { l/min }\end{array}$ & $\begin{array}{c}\text { Welding } \\
\text { speed, } \\
\mathrm{m} / \mathrm{min}\end{array}$ & $\begin{array}{c}\text { Wire } \\
\text { feed } \\
\text { rate, } \\
\mathrm{m} / \mathrm{min}\end{array}$ & $\begin{array}{c}\text { Vibra- } \\
\text { tion am- } \\
\text { plitude, } \\
\mathrm{mm}\end{array}$ & $\begin{array}{c}\text { Vibra- } \\
\text { tion } \\
\text { speed, } \\
\mathrm{mm} / \mathrm{s}\end{array}$ \\
\hline 1 & 52 & 14.5 & $25-30$ & 2.0 & 2.1 & 3.6 & 40 \\
\hline 2 & 60 & 15.0 & $25-30$ & 2.0 & 2.5 & 3.6 & 40 \\
\hline
\end{tabular}

Transverse oscillations of the welding torch were introduced to test the potential for single-pass surfacing for the entire cutting width of the planned steel-titanium bimetal butt joint. The result of surfacing, under mode No. 1 (Table 3), showed the tendency of the surfaced metal to collect in drops (Fig. 3,a). That can be explained by the insufficient heat input. At its increase by increasing the welding current, it was possible to obtain a high-quality regular formation of the surfaced layer (Fig. 3, b). However, at the same time, cracks were observed in the fusion zone due to the formation of intermetallic compounds.
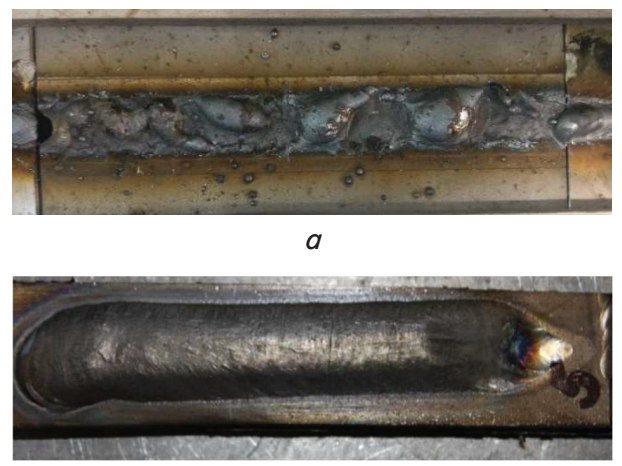

$b$

Fig. 3. General view of beads surfaced with wire ER70S-6 on the plate VT1-0 by the P-GMAW technique under the following modes (Table 3): $a-$ No. $1 ; b-$ No. 2 
According to the data in Table 4, in the transition zone of the steel-titanium sample, surfaced by the P-GMAW technique (Fig. 4), it is possible to assume the formation of TiFe IMP (Spectrum 1 and Spectrum 5) and $\mathrm{Ti}_{2} \mathrm{Fe}$ IMP (Spectrum 2 and Spectrum 3). As regards Spectrum 4 (Table 4), the formation of $\mathrm{Ti}_{2} \mathrm{Fe}$ IMP can also be assumed.

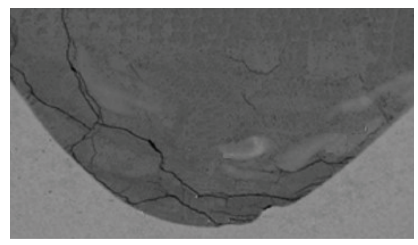

$a$

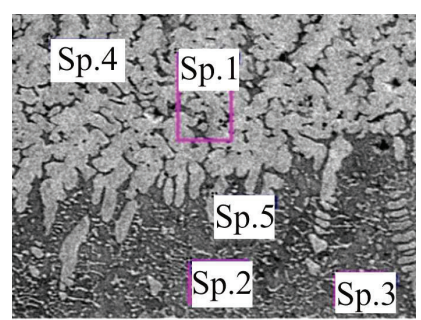

$80 \mu \mathrm{m}$

$b$

Fig. 4. Surfacing steel wire ER70S- 6 on a titanium plate by the P-GMAW technique: $a-$ structure, $\times 50$;

$b$ - steel-titanium transition zone (X-ray spectral microanalysis sites are marked)

Table 4

The content of elements in the local areas shown in Fig. 4, $b$, determined by X-ray spectral microanalysis (XSMA)

\begin{tabular}{|c|c|c|c|c|c|c|}
\hline \multirow{2}{*}{ Spectrum } & \multicolumn{5}{|c|}{ Chemical composition, \% by weight } \\
\cline { 2 - 7 } & $\mathrm{Al}$ & $\mathrm{Si}$ & $\mathrm{Ti}$ & $\mathrm{Mn}$ & $\mathrm{Fe}$ & Total \\
\hline Spectrum 1 & - & 0.51 & 50.62 & 0.72 & 48.15 & 100 \\
\hline Spectrum 2 & 0.29 & 0.6 & 69.04 & 0.41 & 29.66 & 100 \\
\hline Spectrum 3 & 0.44 & 0.43 & 69.09 & 0.5 & 29.54 & 100 \\
\hline Spectrum 4 & 0.5 & 1.6 & 70.85 & 0.75 & 26.31 & 100 \\
\hline Spectrum 5 & 0.24 & 0.14 & 48.34 & 0.5 & 50.77 & 100 \\
\hline
\end{tabular}

The formation of the compounds detected by X-ray spectral microanalysis (XSMA) occurs due to the enrichment of the lower part of the welded steel layer with titanium.

5. 3. Investigating the influence of "cold metal transfer" surfacing on the bead quality and the tendency to form intermetallic phases

During the experiments, we used specialized equipment for CMT ("cold metal transfer") welding made by Fronius (Austria): the power source TPS $4000 \mathrm{CMT}$ and a Robacta Drive CMT burner. The copper wire ER70S-6 was surfaced on a pre-cleaned and degreased plate made of VT1-0 using a protective gas, which was a mixture of $99 \% \mathrm{Ar}+1 \% \mathrm{CO}_{2}$. Surfacing modes are given in Table 5 . The criterion for the preliminary assessment of the suitability of the regime was the absence of visible cracks at the surface and in the fusion zone.

Our metallographic studies of the obtained surfacing under all modes revealed the presence of a complex phase composition at the border of the surfaced layer - base metal.

We have established a significant influence of the welding current value on the structure of the titanium-steel transition zone and the thickness of the IMP layer. Thus, at the point of contact, there is a continuous intermetallic layer. For the samples of titanium-steel surfacing obtained under modes No. 1-3 (Table 5, Fig. 5), it ranges from $400 \mu \mathrm{m}$ to $120 \mu \mathrm{m}$. For the samples under modes No. 4-7 (Table 5) - about 55-35 $\mu \mathrm{m}$. The composition of the solid intermetallic layer varies (wt. \%) from $68.01 \div 70.73 \mathrm{Ti}-31.23 \div 27.98 \mathrm{Fe}-0.49 \div 0.39 \mathrm{Mn}$ of one species to $48.96 \div 49.37 \mathrm{Ti}-49.92 \div 50.53 \mathrm{Fe}-0.71 \div 0.39 \mathrm{Mn}$ of another. In the first case, this approximately corresponds to the composition of the compound of titanium with iron $\mathrm{Ti}_{2} \mathrm{Fe}$, in the second - TiFe, which embrittle the resulting compound. This is followed by the $\alpha$-Fe phase area, enriched with titanium in different percentages for different surfacing modes.

Table 5

Bead surfacing modes using the CMT method

\begin{tabular}{|c|c|c|}
\hline Mode No. & Movement speed, $\mathrm{m} / \mathrm{min}$ & Welding current, $\mathrm{A}$ \\
\hline 1 & 0.5 & 100 \\
\hline 2 & 1.0 & 100 \\
\hline 3 & 1.0 & 75 \\
\hline 4 & 1.0 & 60 \\
\hline 5 & 1.0 & 35 \\
\hline 6 & 1.0 & 30 \\
\hline 7 & 1.5 & 75 \\
\hline 8 & 1.5 & 75 \\
\hline
\end{tabular}

It was found that during surfacing with a welding cur-

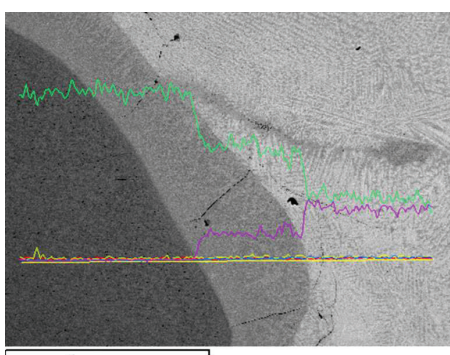

$1 \mathrm{~mm}$

$a$

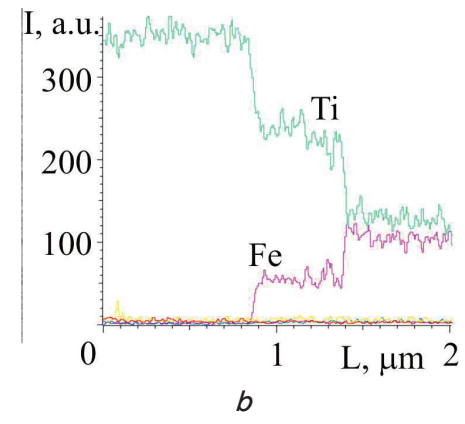

Fig. 5. Surfacing by the "cold metal transfer" method (mode No. 1, Table 3): $a$ - microstructure of the joint; $b$ - distribution of components in the connection area

rent of $100 \mathrm{~A}$ under modes No. 1 and No. 2 (Table 5), cracks were formed in the intermetallic layer of the titanium-steel transition zone (Fig.6). Such sample completely spontaneously cracks after $5 . . .10 \mathrm{~min}$ after surfacing. The destruction occurs along the intermetallic layer from the side of the surfaced metal (Fig. 6, Table 6).

Fig. 6 demonstrates that subject to intense destruction, the transition zone of the surfacing "titanium-steel" corresponds to intermetallic $\mathrm{Ti}_{2} \mathrm{Fe}$ in its chemical composition 
(Spectrum 2, Table 6). Layers of the surfaced steel layer are enriched with titanium to a sufficiently large depth (up to $0.5 \mathrm{~mm}$ ) to form the intermetallic $\mathrm{TiFe}_{2}$ (Spectrum 5, Table 6). The same depth extends to the region of the phase of $\alpha$-Fe, enriched with titanium.

With a decrease in the value of the welding current from 100 to 75 A (mode No. 3, Table 5), the intensity of destruction of steel surfacing on titanium decreases (Fig. 7). The thickness of the intermetallic layer also decreases from $400 \mu \mathrm{m}$ (mode No. 1, Table 5) to $150 \mu \mathrm{m}$.

When the welding current was lowered to $60 \mathrm{~A}$ (mode

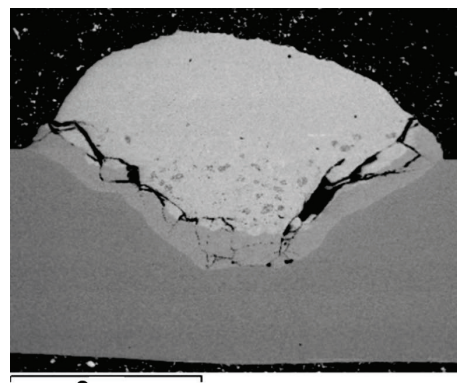

$2 \mathrm{~mm}$

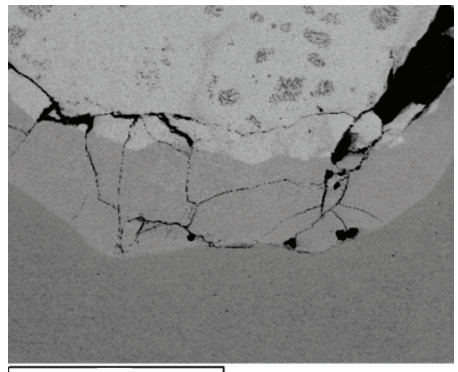

$800 \mu \mathrm{m}$

$b$

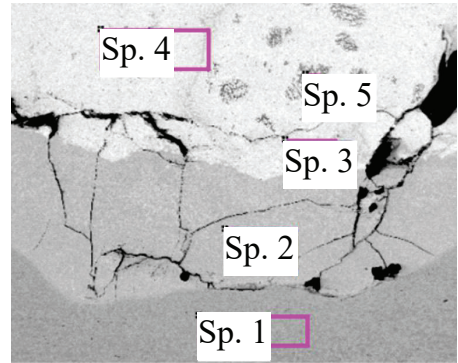

$600 \mu \mathrm{m}$

Fig. 6. Surfacing structures by the CMT method (mode No. 2,

Table 4): $a$ - surfaced bead; $b$ - transition zone; $c-$ indication of microanalysis zones

No. 4, Table 5), no self-destruction of steel surfacing on titanium was observed (Fig. 8). The average size of the $\mathrm{Ti}_{2} \mathrm{Fe}$ intermetallic transition layer was about $55 \mu \mathrm{m}$ with a slight variation in its thickness (Table 7). At the same time, microcracks were found located in a steel surfaced layer parallel to the intermetallic layer at a distance of about $100-200 \mu \mathrm{m}$ from it.

With a decrease in welding current to 35 A (mode No. 5, Table 5), no self-destruction of the surfaced layer occurs but there are microcracks in the zone of the titanium-steel interface boundary, there is also a slight decrease in the thickness of the intermetallic layer. In this layer, the $\mathrm{Ti}_{2} \mathrm{Fe}$ phase is predominantly present (Fig. 9, $a$; Table 8).

Table 6

Results (wt. \%) of quantitative chemical microanalysis of the zones indicated in Fig. 6, c

\begin{tabular}{|c|c|c|c|c|c|c|}
\hline & \multicolumn{6}{|c|}{ Chemical composition, \% by weight } \\
\cline { 2 - 7 } Spectrum & $\mathrm{Al}$ & $\mathrm{Si}$ & $\mathrm{Ti}$ & $\mathrm{Mn}$ & $\mathrm{Fe}$ & Total \\
\hline Spectrum 1 & 0.43 & - & 99.57 & - & - & 100 \\
\hline Spectrum 2 & - & - & 66.56 & - & 33.44 & 100 \\
\hline Spectrum 3 & - & 0.96 & 33.28 & 0.55 & 65.21 & 100 \\
\hline Spectrum 4 & - & 0.73 & 26.23 & 0.99 & 72.05 & 100 \\
\hline Spectrum 5 & - & 1.33 & 24.63 & 1.12 & 72.92 & 100 \\
\hline
\end{tabular}

Results (wt. \%) of quantitative chemical microanalysis of

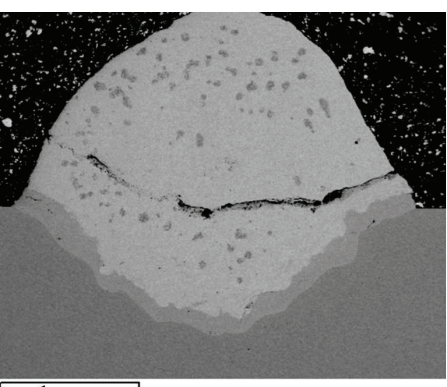

$1 \mathrm{~mm}$

$a$

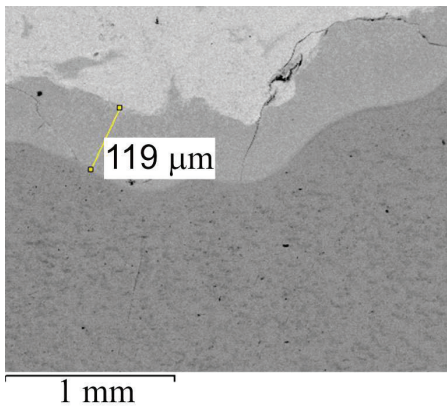

Fig. 7. Structure of steel surfacing on titanium using the CMT method (mode No. 3, Table 5): $a$ - surfaced bead; $b$ - transition zone

elements in the fusion zone of the sample under mode No. 4 (Fig. 8, c)

\begin{tabular}{|c|c|c|c|c|c|c|c|}
\hline \multirow{2}{*}{ Spectrum } & \multicolumn{7}{|c|}{ Chemical composition, \% by weight } \\
\cline { 2 - 8 } & $\mathrm{Al}$ & $\mathrm{Si}$ & $\mathrm{Ti}$ & $\mathrm{Mn}$ & $\mathrm{Fe}$ & $\mathrm{Cu}$ & Total \\
\hline Spectrum 1 & 0.41 & - & 99.59 & - & - & - & 100 \\
\hline Spectrum 2 & - & 0.36 & 68.01 & 0.39 & 31.23 & - & 100 \\
\hline Spectrum 3 & - & 0.72 & 21.59 & 1.09 & 74.98 & 1.62 & 100 \\
\hline Spectrum 4 & - & 0.68 & 16.33 & 1.27 & 79.25 & 2.48 & 100 \\
\hline Spectrum 5 & - & 0.04 & 99.21 & 0.13 & 0.61 & - & 100 \\
\hline
\end{tabular}

At a distance of up to $10 \mu \mathrm{m}$, we find in the steel layer, in some cases, a $\beta$ phase with a high concentration of iron (44.65, wt. \%). The general view of the grains of this phase is similar to the structure of the transition zone of the interface of the bimetal "titanium-steel" obtained by rolling (Fig. 2, Table 2).

Steel beads surfaced at a current of $30 \mathrm{~A}$ on titanium have a minimum number of microcracks, in some cases, microcracks are not detected on microsections (Fig. 9, $b$, 11, Table 8). The presence of the $\mathrm{Ti}_{2} \mathrm{Fe}$, TiFe, and $\mathrm{TiFe}_{2}$ IMPs has been established. The width of the IMP layer was 60...100 $\mu \mathrm{m}$ (Fig. 10). 


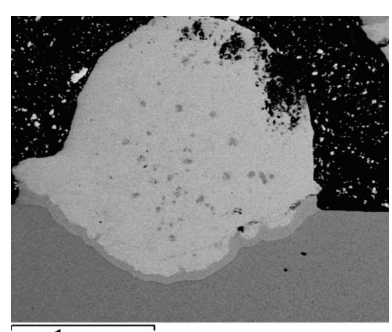

$1 \mathrm{~mm}$

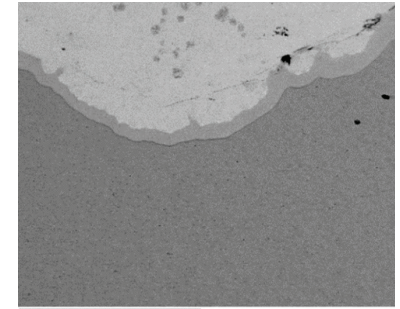

$800 \mu \mathrm{m}$

$b$

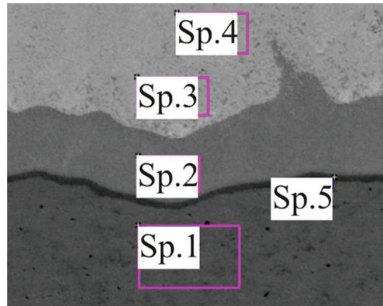

$\overline{100 \mu \mathrm{m}}$

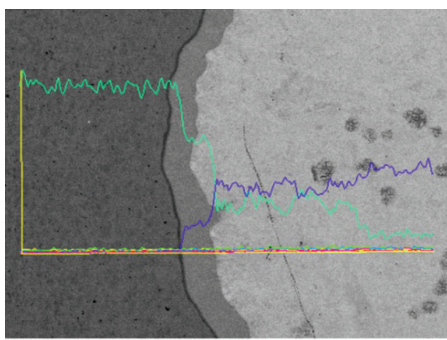

$400 \mu \mathrm{m}$

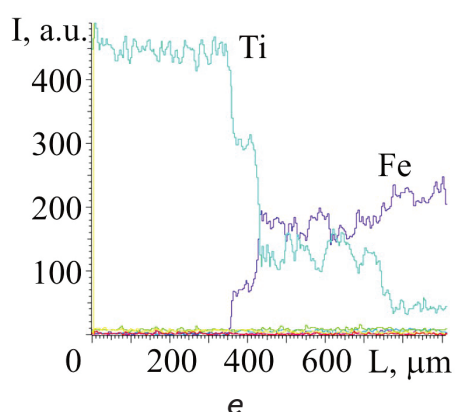

Fig. 8. Structures of steel surfacing on titanium using the CMT method (mode No. 4, Table 5): $a$ - surfaced bead; $b$ - transition zone; fusion zone; $c, d$ - sites for determining the content of elements in the fusion zone; $e$ - distribution of components in the connection zone

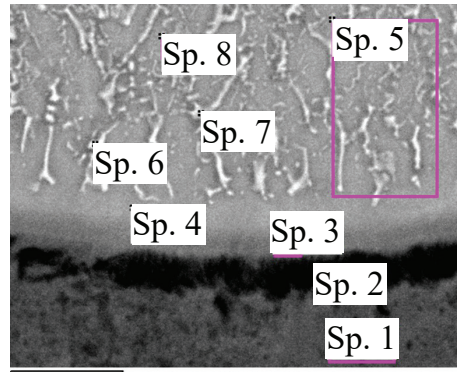

$10 \mu \mathrm{m}$

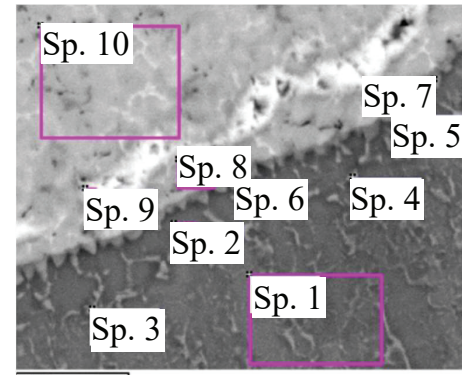

$10 \mu \mathrm{m}$

Fig. 9. Local sites of the matrix of steel surfacing on titanium at which the content of elements was measured (Table 5): $a-$ mode No. 5 (current, $35 \mathrm{~A}$ ); $b$ - mode No, 6 (current, $30 \mathrm{~A}$ )

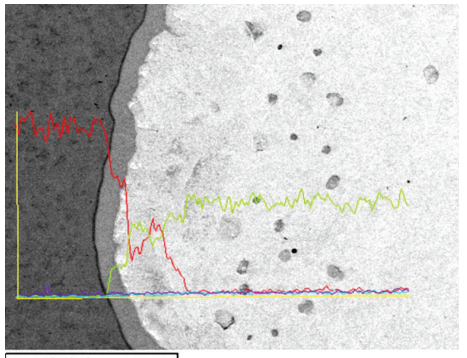

$300 \mu \mathrm{m}$ $a$

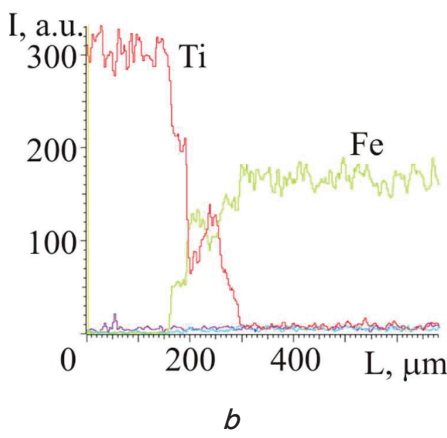

Fig. 10. The surfacing of steel on titanium at a current of $30 \mathrm{~A}$ (mode No. 6, Table 5): $a-$ microstructure of the connection; $b$-distribution of components in the connection zone

In general, the matrix of the steel layer surfaced on titanium at the edge of the solid intermetallic layer is an $\alpha$ phase containing from $74.36 \%$ to $80.81 \%$ iron and the inclusion of the intermetallic $\mathrm{TiFe}_{2}$. Further in height, the surfaced metal contains approximately $80-90 \%$ iron or more, which corresponds to the diagram of the state of the titanium-iron system (from the side of iron, the eutectics $\mathrm{TiFe}_{2}+\alpha$-Fe crystallizes).

5. 4. Investigating the influence of plasma surfacing by indirect arc on the bead quality and the tendency to form intermetallic phases

Plasma surfacing by an indirect arc with a conductive filler wire ("soft plasma") was performed

Table 8

The content of the elements at local sites shown in Fig. 9, determined by X-ray spectral microanalysis (XSMA)

\begin{tabular}{|c|c|c|c|c|c|c|c|c|c|c|c|}
\hline \multirow{2}{*}{ Spectrum } & \multicolumn{5}{|c|}{ Mode No. 5 } & \multicolumn{5}{c|}{ Mode No. 6 } \\
\cline { 2 - 14 } & \multicolumn{4}{|c|}{ Chemical composition, \% by weight } & \multicolumn{4}{c|}{ Chemical composition, \% by weight } \\
\cline { 2 - 14 } & $\mathrm{Al}$ & $\mathrm{Si}$ & $\mathrm{Ti}$ & $\mathrm{Mn}$ & $\mathrm{Fe}$ & $\mathrm{Total}$ & $\mathrm{Si}$ & $\mathrm{Ti}$ & $\mathrm{Mn}$ & $\mathrm{Fe}$ & Total \\
\hline Spectrum 1 & 0.42 & - & 99.58 & - & - & 100 & - & 68.08 & 0.46 & 31.46 & 100 \\
\hline Spectrum 2 & 0.4 & - & 98.92 & - & 0.68 & 100 & 0.46 & 67.78 & 0.88 & 30.88 & 100 \\
\hline Spectrum 3 & 0.39 & - & 91 & - & 8.61 & 100 & 0.37 & 62.39 & 0.43 & 36.80 & 100 \\
\hline Spectrum 4 & - & 0.17 & 73.33 & 0.45 & 26.05 & 100 & 0.6 & 62.74 & 0.58 & 36.08 & 100 \\
\hline Spectrum 5 & - & 0.31 & 68.23 & 0.3 & 31.16 & 100 & 0.11 & 51.13 & 0.49 & 48.27 & 100 \\
\hline Spectrum 6 & - & 0.4 & 61.53 & 0.17 & 37.9 & 100 & 0.24 & 51.73 & 0.51 & 47.53 & 100 \\
\hline Spectrum 7 & - & 0.29 & 63.73 & 0.75 & 35.23 & 100 & 0.17 & 52.56 & 0.56 & 46.71 & 100 \\
\hline Spectrum 8 & - & 0.31 & 68.05 & 0.58 & 31.05 & 100 & 0.76 & 26.35 & 0.99 & 71.91 & 100 \\
\hline Spectrum 9 & - & - & - & - & - & - & 0.98 & 25.49 & 0.92 & 72.61 & 100 \\
\hline Spectrum 10 & - & - & - & - & - & - & 0.66 & 29.46 & 0.94 & 68.93 & 100 \\
\hline
\end{tabular}
using a power source for TIG welding, Tetrix $421 \mathrm{AC} / \mathrm{DC}$, and a separate filler wire feeder mechanism.

The peculiarity of the technique of plasma surfacing by an indirect arc with a conductive filler wire is that the electric arc burning between the tungsten electrode and the filler wire is blown by an additional gas flow. The difference from the process of surfacing with a compressed arc is to provide less compression of the welding arc. That helps reduce its penetration into the base metal and increase the width of the surface heating zone with a lower concentration of energy in it. Compared to conventional TIG-welding, the technique of plasma surfacing by an indirect arc with a conductive filler wire has greater spatial stability. 
The surfacing modes were selected taking into consideration the minimization of the impact of the arc on the titanium sheet. The surfacing zone was intensively protected by argon to prevent the absorption of nitrogen, oxygen, and hydrogen from the surrounding atmosphere by the heated titanium. We considered 2 options for surfacing - with a gap between the filler wire and the article, and without a gap. Surfacing modes are given in Table 9. The general view of surfacing is shown in Fig. 11.

We assessed the suitability of a surfacing mode at the first stage based on the results of a visual inspection of the surfaced beads. It was necessary to ensure the absence of surface defects in the form of pores, non-metallic inclusions, and cracks at the surface of the beads and in the fusion zone.

At the second stage, we performed the metallographic studies of surfacing. All samples obtained under modes No. 1-10 demonstrated intermetallic layers at the "surfaced layer-base metal" interface. At the point of contact, there is a continuous layer of IMP of the maximum thickness (Tables 9, 10):

- from $103 \mu \mathrm{m}$ to $84.6 \mu \mathrm{m}$ for the samples obtained under modes No. 1 , No. 3, No. 4;

- about $70-30 \mu \mathrm{m}$ for the samples under modes No. 2 and No. 5-10. The thickness of the intermetallic layer along the perimeter of the surfacing is not constant (Table 10); the maximum spread is demonstrated by sample No.6, minimum - samples No. 3-5.

The beads surfaced by plasma surfacing with an indirect arc with a conductive filler wire often demonstrate both individual large pores up to $20 \mu \mathrm{m}$ and microporosity. The first place in terms of quality is taken by the samples that were made under mode No. 9 (Fig. 12) with a minimum volume of the surfaced metal; the second - by the samples that were made under mode No. 4 (Fig. 13, $a$; Tables 9,10$)$. The sample that was made under mode No. 5 (Fig. 13, b) is close in the quality of formation of the surfaced bead to the sample that was made under mode No. 4; the minimum number of cracks was observed. The rest of the samples have cracks. Cracking originates and occurs mainly in the boundary places of surfacing on the base metal, having a dendritic structure (Fig. 13). When the heat input is reduced to a certain level (for example, mode No. 5), the following phases (Table 11) are observed in the fusion zone: $\mathrm{TiFe}_{2}$ (Spectrum 1), TiFe (Spectrum 2), and $\mathrm{Ti}_{2} \mathrm{Fe}$ (Spectrum 3). With a further decrease in heat input, the $\mathrm{TiFe}_{2}$ phase may be absent.

Table 9

\section{conductive filler wire}

\begin{tabular}{|c|c|c|c|c|c|}
\hline $\begin{array}{l}\text { Mode } \\
\text { No. }\end{array}$ & $\begin{array}{l}\text { Current } \\
\text { power, A }\end{array}$ & $\begin{array}{c}\text { Wire feed } \\
\text { rate, } \\
\mathrm{m} / \mathrm{min}\end{array}$ & \begin{tabular}{|l} 
Surfacing \\
speed, \\
$\mathrm{cm} / \mathrm{min}$ \\
\end{tabular} & $\begin{array}{c}\text { Gap between } \\
\text { electrode and } \\
\text { part, } \mathrm{mm}\end{array}$ & Note \\
\hline 1 & 60 & 1.55 & 50 & 3 & Wire is in contact with a part \\
\hline 2 & 60 & 1.55 & 50 & 3.5 & Wire at a distance of $0.5 \mathrm{~mm}$ from a part \\
\hline 3 & 62 & 1.55 & 45 & 4 & Wire at a distance of $1.0 \mathrm{~mm}$ from a part \\
\hline 4 & 70 & 1.7 & 60 & 3 & $\begin{array}{c}\text { Wire touches a part; titanium sheet is inten- } \\
\text { sively cooled from the bottom }\end{array}$ \\
\hline 5 & 75 & 1.7 & 60 & 3 & $\begin{array}{l}\text { Wire touches a part; titanium sheet is inten- } \\
\text { sively cooled from the bottom }\end{array}$ \\
\hline 6 & 80 & 1.7 & 60 & 3 & $\begin{array}{c}\text { Wire touches a part; titanium sheet is inten- } \\
\text { sively cooled from the bottom. The surface } \\
\text { of the part is mechanically machined before } \\
\text { surfacing }\end{array}$ \\
\hline 7 & 60 & 1.55 & 55 & 3 & $\begin{array}{c}\text { Wire touches a part; titanium sheet is inten- } \\
\text { sively cooled from the bottom. The surface } \\
\text { of the part is mechanically machined before } \\
\text { surfacing }\end{array}$ \\
\hline 8 & 63 & 1.55 & 55 & 3 & $\begin{array}{c}\text { Wire touches a part; titanium sheet is inten- } \\
\text { sively cooled from the bottom. The surface } \\
\text { of the part is mechanically machined before } \\
\text { surfacing }\end{array}$ \\
\hline 9 & 67 & 1.55 & 60 & 3 & $\begin{array}{c}\text { Wire touches a part; titanium sheet is inten- } \\
\text { sively cooled from the bottom. The surface } \\
\text { of the part is mechanically machined before } \\
\text { surfacing }\end{array}$ \\
\hline 10 & 65 & 1.55 & 55 & 3 & $\begin{array}{c}\text { Wire touches a part; titanium sheet is inten- } \\
\text { sively cooled from the bottom. The surface } \\
\text { of the part is mechanically machined before } \\
\text { surfacing }\end{array}$ \\
\hline
\end{tabular}

Table 10

Thickness of the IMP layer in surfacing when using the technique of plasma surfacing with an indirect arc with a conductive filler wire

\begin{tabular}{|c|c|}
\hline Sample under mode No. & IMP layer thickness, $\mu \mathrm{m}$ \\
\hline 1 & $84.6-98.5$ \\
\hline 2 & $49.4-57.1$ \\
\hline 3 & $100-102$ \\
\hline 4 & $102-103$ \\
\hline 5 & $80.9-81.6$ \\
\hline 6 & $24.7-53.9$ \\
\hline 7 & $73.1-74.0$ \\
\hline 8 & $70.8-72.3$ \\
\hline 9 & $63.9-75.4$ \\
\hline 10 & $52.3-70.0$ \\
\hline
\end{tabular}

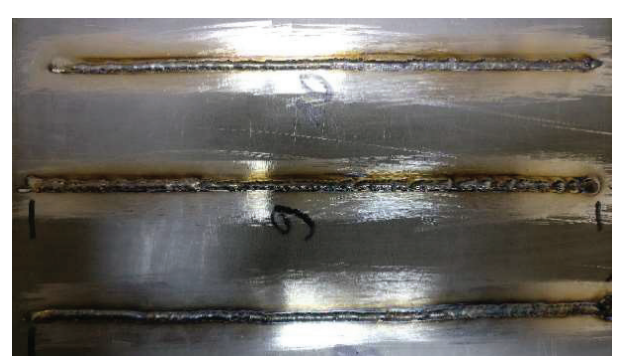

Fig. 11. General view of ER70S-6 beads, surfaced by the technique of plasma surfacing with an indirect arc with a conductive filler wire on the plate VT1-0 


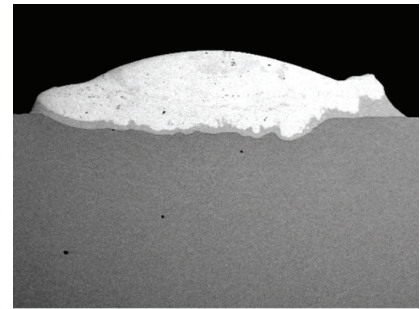

$1 \mathrm{~mm}$

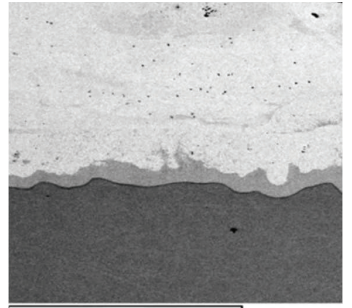

$800 \mu \mathrm{m}$

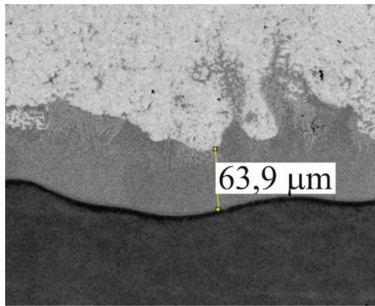

$100 \mu \mathrm{m}$ $c$

Fig. 12. Structures of the cross-sections of the bead surfaced by the technique of plasma surfacing with an indirect arc with a conductive filler wire under mode No. 9 (Table 9)

5. 5. Investigating the influence of plasma-arc surfacing on the bead quality and the tendency to form intermetallic phases

To perform plasma-arc welding (PAW), a current-carrying wire-anode was used, on which the arc of the plasma torch burned. The wire positioner was fixed on a plasma torch that had the ability to execute transverse oscillations to increase the width of the welded bead. Surfacing was performed using a power source for TIG welding,

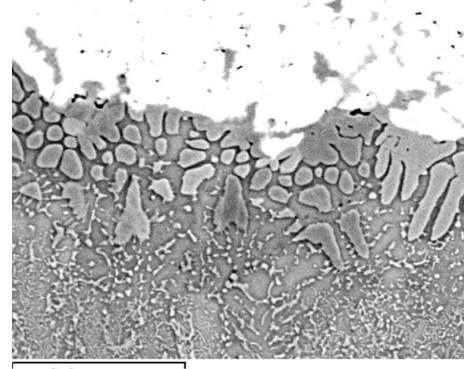

$30 \mu \mathrm{m}$

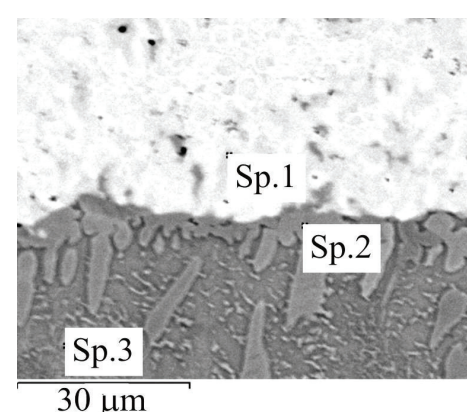

$b$

$30 \mu \mathrm{m}$
Fig. 13. Structures of the transition zone steel-titanium, obtained by plasma surfacing with an indirect arc with a conductive filler wire (Tables 9, 10): $a$ - mode No. $4 ; b-$ mode No. 5

The content of elements in the local areas (Fig. 13, b) of the surfaced steel wire on titanium under mode No. 5 (Table 9), determined by the method of X-ray spectral microanalysis (XSMA)

\begin{tabular}{|c|c|c|c|c|c|}
\hline \multirow{2}{*}{ Spectrum } & \multicolumn{5}{|c|}{ Chemical composition, \% by weight } \\
\cline { 2 - 6 } & $\mathrm{Si}$ & $\mathrm{Ti}$ & $\mathrm{Mn}$ & $\mathrm{Fe}$ & Total \\
\hline Spectrum 1 & 0.6 & 30.5 & 0.96 & 67.94 & 100 \\
\hline Spectrum 2 & 0.22 & 48.92 & 0.67 & 50.2 & 100 \\
\hline Spectrum 3 & 0.29 & 67.51 & 0.57 & 31.62 & 100 \\
\hline
\end{tabular}

We used a sample obtained without cracks under mode No. 9 to study the composition of a continuous intermetallic layer. The chemical composition varies (wt. \%) from $67.69 \div 68.09 \mathrm{Ti}-31.03 \div 31.46 \mathrm{Fe}-0.44 \div 0.59 \mathrm{Mn}$ of one species to $48.05 \div 49.5 \mathrm{Ti}-49.75 \div 51.16 \mathrm{Fe}-0.67 \mathrm{Mn}$ of another. In the first case, this approximately corresponds to the composition of the compound of titanium with iron $\mathrm{Ti}_{2} \mathrm{Fe}$, in the second - TiFe. This is followed by a phase of $\alpha$-Fe enriched with titanium. The matrix of the surfaced layer at the edge of the continuous intermetallic layer is an $\alpha$ phase containing $68.16 \%$ Fe and $29.88 \%$ Ti. Further in height, the surfaced metal contains approximately $90 \% \mathrm{Fe}$, on the iron side, the eutectics $\mathrm{TiFe}_{2}+\alpha$-Fe crystallizes.
Table 11

Tetrix 421 AC/DC, a plasma module, and a separate filler wire feeder mechanism.

The copper wire ER70S-6 was surfaced on a precleaned and degreased plate made of VT1-0 using a protective gas of argon. Surfacing modes are given in Table 12. The diameter of the plasma-forming nozzle was changed from $2 \mathrm{~mm}$ (mode No. 1) to $4 \mathrm{~mm}$ (other modes).

During the experiments, it was found that increasing the concentration of energy due to compressing the arc with a nozzle of smaller diameter (mode No. 1, Table 12) does not make it possible to obtain high-quality formation of seams. With welding currents of $60 \ldots 90 \mathrm{~A}$ (modes No.1-4, Table 12), the heat input is insufficient, the surfaced metal is collected in drops, the formation of a homogeneous bead is difficult (Fig. 14, $a$ ). When the welding current increases to $130 \mathrm{~A}$ (mode No. 5, Table 12), the heat input increases, which significantly improves the formation of the surfaced layer (Fig. 14, $b$ ).

Cracks were observed in all surfaced beads (modes No. 1-5). Especially clearly the grid of cracks was expressed on th properly formed bead (Fig. 14,b). This is due to the IMP formation through the enrichment of the lower part of the surfaced steel layer with titanium.

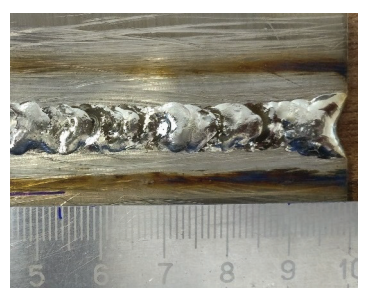

a

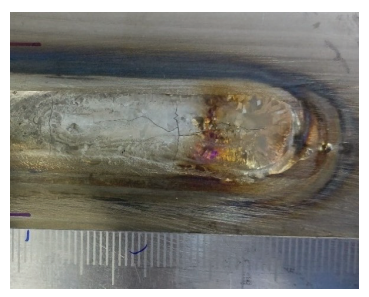

$b$
Fig. 14. General view of surfacing (Table 12):

Table 12

Plasma-arc surfacing modes with a conductive filler wire (PAW)

\begin{tabular}{|c|c|c|c|c|c|c|c|c|c|c|c|}
\hline $\begin{array}{c}\text { Mode } \\
\text { No. }\end{array}$ & $\begin{array}{l}\text { Weld- } \\
\text { ing cur- } \\
\text { rent, A }\end{array}$ & $\begin{array}{c}\text { Arc } \\
\text { volt- } \\
\text { age, } \\
\text { V }\end{array}$ & Gas & $\begin{array}{c}\text { Plas- } \\
\text { ma-form- } \\
\text { ing gas } \\
\text { glow rate, } \\
\text { l/min }\end{array}$ & $\begin{array}{c}\text { Protec- } \\
\text { tive gas } \\
\text { flow rate, } \\
1 / \mathrm{min}\end{array}$ & $\begin{array}{c}\text { Boot gas } \\
\text { con- } \\
\text { sump- } \\
\text { tion, } \\
\text { l/min }\end{array}$ & $\begin{array}{c}\text { Blowing } \\
\text { gas con- } \\
\text { sumption, } \\
\text { 1/min }\end{array}$ & $\begin{array}{l}\text { Weld- } \\
\text { ing } \\
\text { speed, } \\
\mathrm{m} / \mathrm{min}\end{array}$ & $\begin{array}{l}\text { Wire } \\
\text { feed } \\
\text { rate, } \\
\mathrm{m} / \mathrm{min}\end{array}$ & $\begin{array}{c}\text { Vibration } \\
\text { ampli- } \\
\text { tude, } \\
\text { mm }\end{array}$ & $\begin{array}{l}\text { Vibration } \\
\text { speed, } \\
\mathrm{mm} / \mathrm{s}\end{array}$ \\
\hline 1 & 60 & 17.6 & $\mathrm{Ar}$ & 3.5 & 25 & 30 & 30 & 2.0 & 1 & 7 & 40 \\
\hline 2 & 80 & 20 & Ar & 0.6 & 25 & 30 & 30 & 2.0 & 0.7 & 6 & 40 \\
\hline 3 & 85 & 20 & Ar & 0.6 & 25 & 30 & 30 & 2.0 & 0.7 & 7 & 40 \\
\hline 4 & 90 & 20 & Ar & 0.6 & 25 & 30 & 30 & 2.0 & 0.7 & 6.6 & 40 \\
\hline 5 & 130 & 24 & Ar & 0.4 & 25 & 30 & 30 & 2.0 & 0.8 & 5.6 & 40 \\
\hline
\end{tabular}

$a-$ mode No. 4 ; $b-$ mode No. 5 


\section{Discussion of results of applying various techniques of arc welding for connecting sheets of titanium-clad steel}

Our study aimed to determine regularities of interphase interaction, the features of IMP formation, as well as defects when surfacing steel on titanium. We have considered four techniques: P-MAG, CMT, plasma surfacing with an indirect arc with a current-driving filler wire, and PAW.

Among the main regularities worth noting are tendencies to increase the thickness of the IMP layer with an increase in current and a decrease in the rate of surfacing (that is, with an increase in heat input). In all the obtained compounds, in the zone of interaction of the melt of steel with titanium, a continuous layer of IMP is formed, having an average thickness in the range of 400 to $25 \mu \mathrm{m}$. The thickness of this layer depends not only on the heat input into the surfaced sample but also on the technique of surfacing used. Its greatest thickness is observed in the case of surfacing by the PAW technique (about $400 \mu \mathrm{m}$ ), the smallest - by plasma surfacing with an indirect arc with a conductive filler wire $(25 \ldots 54 \mu \mathrm{m}$, mode No. 6, Table 9$)$.

The composition of the solid layer of IMP varies. Typically, it is (wt. \%) $68.01 \div 70.73 \mathrm{Ti}-31.23 \div 27.98 \mathrm{Fe}-$ $0.49 \div 0.39 \mathrm{Mn}$, or $48.96 \div 49.37 \mathrm{Ti}-49.92 \div 50.53 \mathrm{Fe}-$ $0.71 \div 0.39 \mathrm{Mn}$. In the first case, this approximately corresponds to the composition of the $\mathrm{Ti}_{2} \mathrm{Fe}$ compound, in the second - TiFe. In several examples (usually with a greater heat input), the $\mathrm{TiFe}_{2}$ phase is also observed. Such IMPs embrittle the resulting compound. This is followed by a phase area of $\alpha$-Fe, enriched with titanium in different percentages for different surfacing modes. The formation of such structures contributes to the cracking of surfaced steel beads and, in some cases, their complete detachment from the titanium sheet.

When using the CMT technique, it was found (Fig. 7) that the transition zone of the titanium-steel surfacing underwent intense destruction. According to the chemical composition, it corresponds to the intermetallic $\mathrm{Ti}_{2} \mathrm{Fe}$ (spectrum 2, Table 6; spectrum 2, Table 7; spectra 5-8 of mode No. 5, Table 8; spectra $1-4$ of mode No. 6 , Table 8; spectrum 3, Table 11). The presence of the TiFe phase was also detected (spectra 5-7 of mode No. 6, Table 8; spectrum 2, Table 11). Layers of the surfaced steel layer are enriched with titanium to a sufficiently large depth (up to $0.5 \mathrm{~mm}$ ) to form the intermetallic $\mathrm{TiFe}_{2}$ (spectrum 5, Table 6; spectra 8-10 of mode No. 6, Table 8; spectrum 1 , Table 11). The region of the phase of $\alpha$-Fe, enriched with titanium, similarly propagates in depth. Close results were received when studying the surfacing by the plasma surfacing with an indirect arc with a conductive filler wire and the P-MAG technique under the modes with reduced heat input. The main difference of P-MAG is the predominant formation of the $\mathrm{Ti}_{2} \mathrm{Fe}$ and $\mathrm{TiFe}$ phases in the steel-titanium transition zone. That indicates the possibility, when using the techniques of CMT, plasma surfacing by an indirect arc with a conductive filler wire, and P-MAG for welding steel on titanium, to form a controversial phase of $\mathrm{Ti}_{2} \mathrm{Fe}$.

When surfacing with a higher heat input, both sides of the fusion boundary, both in steel and titanium, reveal a dendritic structure. In combination with IMP, it can contribute to the evolution of cracks. Such cracks are usually a grid. With a decrease in heat input, the dendritic structure is left only in the surfaced steel, the mesh of cracks is replaced by individual cracks. With minimal heat inputs achieved, there was an almost complete absence of dendritic structure in the fusion zone. The number of cracks was minimal, or there were no cracks at all.

The application of the technique of plasma surfacing by an indirect arc with a current-carrying filler wire (mode No. 6, Table 9) reduced the thermal effect on the base metal. In this case, at the boundary of the transition of steel-titanium, the composition and microstructure of IMP layers, in some cases, approach the composition and structure of the transition zone of the bimetallic sheet "titanium-steel" (Fig. 2, Table 2). The difference in the structure of the bimetallic sheet is the small thickness of IMP layers and supersaturated solid solutions:

- layers up to $5 \mu \mathrm{m}$ thick from the $\beta$ phase, with an iron concentration of $44.65 \%$ by weight;

- layers up to $0.2 \ldots 0.4 \mu \mathrm{m}$ thick of the composition close to TiFe intermetallic.

Thus, our study has demonstrated the following features of the metallurgical interaction that occur when using various techniques of arc and plasma surfacing of steel wire on titanium:

1. The main disadvantage of all the techniques considered is the general tendency of IMP emergence when surfacing steel on titanium. Distinctive features are in the thickness of the IMP layers, their composition, the intensity of cracking of the fusion zone and the surfaced bead in general, the quality of the formation of this bead. Thus, the technique of plasma surfacing by an indirect arc with a current-carrying filler wire is the least sensitive to the formation of these defects and makes it possible to obtain IMP layers of the minimum thickness $(25 \ldots 54 \mu \mathrm{m}$ or less) in combination with the best quality of forming the surfaced metal beads.

2. Further minimization of the size of the IMP layer is hampered by a critical decrease in the heat input into the metal, which leads to the tendency of the surfaced metal to be collected in separate droplets.

3. In the transition zone of steel surfacing on titanium, we observed the formation of the intermetallic phases $\mathrm{TiFe}_{2}, \mathrm{TiFe}$, and the phase of $\alpha$-Fe, enriched with titanium in different percentages for different techniques and modes of surfacing. With low heat input, the study has shown the possibility of forming the TiFe and $\mathrm{Ti}_{2} \mathrm{Fe}$ phases. The presence of the latter until today has been considered controversial.

4. It was determined that the minimization of the thermal effect on titanium (observed when using the technique of plasma surfacing with an indirect arc with a current-carrying filler wire) at the steel-titanium fusion boundary, in some cases, brings the phase composition and structure of the formed layers closer to the composition and structure of the transition zone of the original bimetallic sheet obtained by rolling, that is, there are layers up to $5 \mu \mathrm{m}$ thick from the $\beta$ phase with an iron concentration of $44.65 \%$ by weight, and the intermetallic layers up to $0.2 \ldots 0.4 \mu \mathrm{m}$ thick, close in composition to the TiFe phase.

Further advancement of our research could involve devising, on its basis, a new surfacing process, in which a barrier layer protecting against the formation of IMP is introduced between titanium and steel. At the same time, minimizing the thermal effect of steel surfacing on the 
titanium base is ensured using the processes and modes described in this work. Thus, for applying a barrier layer to titanium when connecting the bimetal "steel-titanium", it is advisable to use the process of plasma surfacing with an indirect arc with a conductive filler wire. It is possible to replace or supplement this technique with the CMT or P-GMAW/P-MAG process. After applying the barrier layer, to reduce its mixing and the overall level of heat input, it is necessary to reduce the volume of steel applied in the first pass. The specified techniques of surfacing are also suitable for this purpose.

\section{Conclusions}

1. The following techniques of arc surfacing of steel on titanium were chosen for our study: P-GMAW/P-MAG, CMT, plasma surfacing with an indirect arc with a conductive filler wire, PAW. When they were used, a general trend in IMP emergence was established. The application of these techniques makes it possible to reduce heat input into the metal to reduce the thickness of the IMP layer. However, when certain critical values are reached, that leads to the fact that, instead of forming a high-quality surfaced bead, the metal is collected in separate drops.

2. When surfacing by using the P-GMAW/P-MAG technique, the minimization of heat input is limited by the quality and uniformity of the formation of beads at welding currents above $50 \mathrm{~A}$, which does not make it possible to achieve high thermal locality. That leads to the formation in the transition zone of steel-titanium a layer of IMP with a thickness of $60 \ldots 80 \mu \mathrm{m}$. Based on X-ray spectral microanalysis, it is possible to assume the presence of $\mathrm{TiFe}$ and $\mathrm{Ti}_{2} \mathrm{Fe}$ IMPs in this layer. The formation of these compounds occurs due to the enrichment of the lower part of the surfaced steel layer with titanium.

3. Surfacing by the CMT technique makes it possible to conduct the process with low heat input at minimum (above $30 \mathrm{~A})$ currents. That helps minimize the thickness of the IMP layer (from $\sim 40 \mu \mathrm{m}$ ). At such surfacing, based on X-ray spectral microanalysis, we can assume the presence of $\mathrm{Ti}_{2} \mathrm{Fe}$, TiFe, and $\mathrm{TiFe}_{2}$ compounds.

4. The technique of plasma surfacing by an indirect arc with a conductive filler wire is the least sensitive to IMP formation. The resulting intermetallic layer has a minimum (compared to other techniques) thickness in combination with the best quality in the formation of the surfaced metal beads. It includes the compounds of $\mathrm{TiFe}_{2}$, TiFe, and $\mathrm{Ti}_{2} \mathrm{Fe}$. Reducing the thermal effect on the base metal at the boundary of the transition of the surfaced steel bead on titanium has a positive effect on the structure of the resulting layers. In some cases, that makes it possible to approximate the phase composition and structure of the transition zone to those observed in the original bimetallic sheet "steel-titanium" obtained by rolling. Layers up to $5 \mu \mathrm{m}$ thick from the $\beta$ phase with an iron concentration of $44.65 \%$ by weight are observed, as well as the layers of IMP up to $0.2 \ldots 0.4 \mu \mathrm{m}$ thick, close in composition to the TiFe phase.

5 . When surfacing by the PAW technique, the energy concentration increases due to the compression of the arc, which does not make it possible to obtain the high-quality formation of joints with insufficient heat input (welding currents of $60 \ldots 90 \mathrm{~A}$ ), leading to the collection of the surfaced metal drops. With an increase in heat input due to an increase in welding current (up to $130 \mathrm{~A}$ ), the formation of the surfaced layer is noticeably improved, a homogeneous bead is formed. However, this leads to a significant increase in the thickness of the IMP layer due to the enrichment of the lower part of the welded steel layer with titanium and a grid of cracks on the formed beads.

\section{Acknowledgments}

This work was funded within the framework of the fundamental departmental research by the National Academy of Sciences of Ukraine "Studying the regularities in the progress of the physical and metallurgical processes that form intermetallic phases during the plasma-arc welding of the steel-titanium bimetal with applied protective layers" (State registration number $0118 \mathrm{U} 100524)$.

\section{References}

1. Nakamura, S., Homma, K. (2000). Durability of Titanium-Clad Steel Plates used as an Anti-Corrosion System. Structural Engineering International, 10 (4), 262-265. doi: https://doi.org/10.2749/101686600780481338

2. Su, H., Luo, X., Chai, F., Shen, J., Sun, X., Lu, F. (2015). Manufacturing Technology and Application Trends of Titanium Clad Steel Plates. Journal of Iron and Steel Research International, 22 (11), 977-982. doi: https://doi.org/10.1016/s1006-706x(15)30099-6

3. Abdul Karim, M., Park, Y.-D. (2020). A Review on Welding of Dissimilar Metals in Car Body Manufacturing. Journal of Welding and Joining, 38 (1), 8-23. doi: https://doi.org/10.5781/jwj.2020.38.1.1

4. Tomashchuk, I., Sallamand, P. (2018). Metallurgical Strategies for the Joining of Titanium Alloys with Steels. Advanced Engineering Materials, 20(6), 1700764. doi: https://doi.org/10.1002/adem.201700764

5. Rabkin, D. M., Ryabov, V. R., Gurevich, S. M. (1975). Svarka raznorodnyh metallov. Moscow: Tekhnika, 208.

6. Diagramma sostoyaniya sistemy zhelezo - titan (Fe-Ti). Available at: https://markmet.ru/diagrammy-splavov/diagrammasostoyaniya-sistemy-zhelezo- $\%$ E2\%80\%93-titan-fe-ti

7. Murray, J. L. (1981). The Fe-Ti (Iron-Titanium) system. Bulletin of Alloy Phase Diagrams, 2 (3), 320-334. doi: https://doi.org/ $10.1007 / \mathrm{bf} 02868286$

8. Bo, H., Wang, J., Duarte, L., Leinenbach, C., Liu, L., Liu, H., Jin, Z. (2012). Thermodynamic re-assessment of Fe-Ti binary system. Transactions of Nonferrous Metals Society of China, 22 (9), 2204-2211. doi: https://doi.org/10.1016/s1003-6326(11)61450-7

9. Mannucci, A., Tomashchuk, I., Mathieu, A., Bolot, R., Cicala, E., Lafaye, S., Roudeix, C. (2020). Use of pure vanadium and niobium/ copper inserts for laser welding of titanium to stainless steel. Journal of Advanced Joining Processes, 1, 100022. doi: https://doi.org/ 10.1016/j.jajp.2020.100022 
10. Pardal, G., Ganguly, S., Williams, S., Vaja, J. (2016). Dissimilar metal joining of stainless steel and titanium using copper as transition metal. The International Journal of Advanced Manufacturing Technology, 86 (5-8), 1139-1150. doi: https://doi.org/10.1007/ s00170-015-8110-2

11. Kirik, I. (2016). Weldability of Ti6Al4V to AISI 2205 with a nickel interlayer using friction welding. Materiali in Tehnologije, 50 (3), 353-356. doi: https://doi.org/10.17222/mit.2015.039

12. Peleshenko, S., Korzhyk, V., Voitenko, O., Khaskin, V., Tkachuk, V. (2017). Analysis of the current state of additive welding technologies for manufacturing volume metallic products (review). Eastern-European Journal of Enterprise Technologies, 3 (1 (87)), 42-52. doi: https://doi.org/10.15587/1729-4061.2017.99666

13. Arora, H., Singh, R., Brar, G. S. (2019). Thermal and structural modelling of arc welding processes: A literature review. Measurement and Control, 52 (7-8), 955-969. doi: https://doi.org/10.1177/0020294019857747

14. Selvi, S., Vishvaksenan, A., Rajasekar, E. (2018). Cold metal transfer (CMT) technology - An overview. Defence Technology, 14 (1), 28-44. doi: https://doi.org/10.1016/j.dt.2017.08.002

15. Zhang, Q. L., Fan, C. L., Lin, S. B., Yang, C. L. (2014). Novel soft variable polarity plasma arc and its influence on keyhole in horizontal welding of aluminium alloys. Science and Technology of Welding and Joining, 19 (6), 493-499. doi: https://doi.org/ 10.1179/1362171814y.0000000215

16. Sydorets, V., Korzhyk, V., Khaskin, V., Babych, O., Berdnikova, O. (2017). On the Thermal and Electrical Characteristics of the Hybrid Plasma-MIG Welding Process. Materials Science Forum, 906, 63-71. doi: https://doi.org/10.4028/www.scientific.net/ msf.906.63 